\section{Homeopatia no Sistema Único de Saúde: representações dos usuários sobre o tratamento homeopático}

\author{
Homeopathy in the Unified National Health \\ System in Brazil: users' representations of \\ homeopathic treatment
}

\author{
${ }^{1}$ Instituto de Saúde Coletiva, \\ Universidade Federal da \\ Bahia, Salvador, Brasil. \\ Correspondência \\ D. A. Monteiro \\ Instituto de Saúde Coletiva, \\ Universidade Federal da \\ Bahia. \\ Campus Universitário do \\ Canela, Rua Augusto Vianna \\ $s / n, 2^{\circ}$ andar, Salvador, $B A$ \\ 40110-060, Brasil. \\ dalvamonteiro@compos.com.br
}

\begin{abstract}
Homeopathy was officially introduced in Brazil in 1840 but was only recognized by the Federal Board of Medicine as a medical specialty in 1980. It still has a limited presence in the Unified National Health System (SUS), with only a few homeopathy services in a handful of Brazilian counties. The current study aimed to analyze National Health System users' representations of homeopathy. A case study was conducted in a health unit in Salvador, Bahia State, using a qualitative methodology. Data collection used 112 questionnaires and 19 in-depth interviews with users of homeopathy services. The study results showed that the main motivation for seeking homeopathic treatment was the failure of previous allopathic treatment. The holistic perspective, use of natural medications, longer consultations, and attentive listening to patients appeared as positive characteristics of homeopathy as compared to allopathy. The results point to the potential contribution of alternative therapeutic practices like homeopathy to the Brazilian National Health System.
\end{abstract}

Homeopathy; Social Representations; Single Health System; Complementary Therapies
Dalva de Andrade Monteiro 1

Jorge Alberto Bernstein Iriart 1

\section{Introdução}

A homeopatia chegou oficialmente ao Brasil em 1840, por meio do ex-comerciante francês e militante socialista Benoit Mure 1,2. Há relatos, entretanto, de que, em 1820, os imigrantes alemães, que se estabeleceram em colônias no Sul do Brasil, já a utilizavam como uma medicina caseira e seguiam as orientações presentes nos livros escritos pelo médico conterrâneo e criador da nova medicina, Dr. Samuel Hahnemann 2.

No seu início, a história da homeopatia no Brasil esteve atrelada a uma prática liberal 3 , com tímidas incursões institucionais nos ambulatórios mantidos pelas ordens católicas, no Rio de Janeiro, que prestavam cuidados aos socialmente desassistidos, inclusive, escravos 2 . Os profissionais adeptos e defensores da nova terapêutica sustentaram embates na imprensa e nos órgãos oficiais ligados à saúde, contrapondo-se à elite sócio-econômica que, nos meios acadêmicos, bloqueava a oficialização e acusava a homeopatia de charlatanismo 1 .

Na segunda metade do século XIX, ocorreu a aproximação da homeopatia com o espiritismo kardecista, doutrina religiosa francesa que se disseminou na sociedade brasileira e se propagou entre os médicos, fazendo muitos adeptos, principalmente entre os homeopatas 1 .

No século seguinte, tanto as classes privilegiadas quanto as populares, principalmente na zona rural, tiveram um papel relevante na propagação 
da terapêutica, através das boticas homeopáticas, comercializadas pelos mascates itinerantes, que compunham o arsenal de medicamentos das famílias tradicionais ${ }^{4}$. Concomitantemente, a umbanda começou a ganhar popularidade, e os seus médiuns - homeopatas leigos, como acontecia na Europa 2 - receitavam as "gotinhas" homeopáticas (além dos tradicionais banhos de ervas e beberagens 5), disseminando essa prática nos centros urbanos e zonas rurais, enraizando-a no itinerário terapêutico da massa populacional em crescimento, excluída da assistência médica oficial, e contribuindo para que a homeopatia alcançasse o status de medicina popular 1 .

A expansão da homeopatia nas classes populares ocorreu à margem dos órgãos oficiais de saúde, interiorizando-se pelos vários recantos do Brasil por meio de práticas beneficentes de farmacêuticos, que dispensavam medicamentos gratuitamente, e de médicos que prestavam assistência filantrópica nos hospitais de ordens religiosas, militares ou nos consultórios particulares 4 . Segundo Luz 1, este percurso, de falta de espaço nas instituições médicas públicas e da associação com o catolicismo, o espiritismo e o umbandismo, como forma de resistência e expansão, contribuiu para que, mesmo nos dias atuais, a homeopatia ainda seja considerada para muitos uma medicina religiosa ou mística.

A partir da década de 70, com o acirramento da crise do modelo médico hegemônico, a homeopatia começou a ser vista como uma alternativa terapêutica à "medicina especialista, tecnológica, mercantilizada e marcada pelas terapêuticas invasivas e iatrogênicas" 1 (p. 42), cujas motivações econômico-financeiras, organizacionais e gerenciais de acessibilidade, eficácia, e políticas corporativas e éticas eram alvo de críticas 6,7 . A dimensão cultural dessa crise apontava para o grau de insatisfação dos usuários com o que era oferecido pela medicina oficial, tendo em vista que sua prática mais tecnicista e menos integralizadora, desconsiderava “...a complexa dimensão simbólica da vida social, profundamente implicada na questão da saúde do ser humano e, conseqüentemente, do seu imaginário, de suas representações e rituais milenares sobre as relações entre vida, saúde doença, loucura e morte" 1 (p. 275), favorecendo a busca de terapias nas quais os aspectos simbólicos, psicossociais e existenciais pudessem ser contemplados.

Nas duas últimas décadas, os homeopatas vêm ampliando campos de atuação que lhes têm garantido maior aceitação e credibilidade entre os usuários e nas instituições normativas e prestadoras de serviço de saúde. Reconhecida desde 1980 entre as especialidades médicas regulamentadas pelo Conselho Federal de Me- dicina, a homeopatia tem sido praticada, principalmente, em consultórios médicos particulares e nos ambulatórios dos cursos de formação, ou por disponibilidade de médicos que fazem atendimentos gratuitos à população de baixa renda, muitos deles ligados a grupos que professam a religião espírita 1 .

Em 1998, constatou-se que havia médicos homeopatas atendendo no Sistema Único de Saúde (SUS) em apenas vinte municípios brasileiros; em algumas dessas cidades, as consultas homeopáticas na rede pública eram iniciativas pessoais de médicos homeopatas, que contavam com o apoio do gestor local, permitindo-lhes o exercício da homeopatia nas unidades básicas de saúde, nos serviços mais complexos e nas equipes do Programa Saúde da Família (PSF) ${ }^{8}$. Pouco se sabe, no entanto, sobre como os usuários do SUS se relacionam com a homeopatia e o tratamento homeopático. Visando a contribuir para preencher essa lacuna do conhecimento, este estudo teve por objetivo conhecer as representações dos usuários do SUS sobre a homeopatia. Mais especificamente, buscou-se compreender as motivações dos usuários para procurar a homeopatia, como eles representam e explicam a ação dos medicamentos e o tratamento homeopáticos.

\section{Considerações teóricas}

Segundo Queiroz ${ }^{9}$ (p. 25), as representações sociais são conhecimentos culturalmente carregados, são "um tipo de saber, socialmente negociado, contido no senso comum e na dimensão cotidiana, que permite ao indivíduo uma visão de mundo e o orienta nos projetos de ação e nas estratégias que desenvolve em seu meio social". Cada grupo social constrói códigos culturais que articulam representações sobre diversas esferas sociais, entre as quais se incluem representações sobre corpo, saúde e doença, formando uma matriz cultural ou um sistema simbólico ${ }^{10}$. É a cultura que fornece as lentes através das quais será realizada a leitura dos sinais corporais, contribuindo para determinar se eles serão avaliados como irrelevantes ou se, ao contrário, serão percebidos como indicadores de doença que demande ajuda terapêutica imediata 11. As representações podem, também, influenciar na escolha e na avaliação das alternativas terapêuticas pelos indivíduos, segundo a proximidade ou distanciamento com relação ao contexto cultural em que estão inseridos. Parte-se do pressuposto que os indivíduos, no encontro terapêutico, sempre fazem uma releitura do discurso médico a partir da sua matriz cultural. É importante, então, compreen- 
der como os elementos da racionalidade homeopática são incorporados e reinterpretados pelos usuários do SUS, na cidade de Salvador.

\section{As racionalidades médicas da homeopatia e da biomedicina}

O conceito de racionalidades médicas, defendido por Luz, diz respeito a um sistema de tratamento que, visando a restabelecer a saúde dos seres humanos ou combater doenças, demonstra sua eficácia prática, sendo sustentado por um arcabouço teórico (epistemé) que, por sua vez, traduz a competência empírica (tekné) daquela teoria 12,13. A homeopatia e a biomedicina possuem diferentes racionalidades médicas e ambas podem ser definidas como sistemas médicos complexos, uma vez que são estruturalmente constituídas por cinco dimensões básicas, com abordagens teórico-práticas 12: (1) morfologia humana, ou anatomia; (2) dinâmica vital, ou fisiologia; (3) doutrina médica, ou corpus doutrinário; (4) sistema de diagnose e (5) sistema terapêutico. As racionalidades médicas da biomedicina e da homeopatia têm na medicina moderna uma origem comum; Hahnemann, inclusive, era um clínico conceituado, que fazia uso das técnicas e da terapêutica de seu tempo 1 . Nesses dois séculos de convivência, entretanto, a homeopatia ocupou uma posição marginal em relação à biomedicina, uma vez que esta, legitimada pelo grande desenvolvimento tecnológico e pela ocupação competente de espaços e papéis sociais, transformou-se na medicina que responde às demandas (ainda que questionável em algumas oportunidades) de saúde e dá sustentação ao modelo econômico dominante no mundo ocidental 6 .

Foucault 14 data o nascimento da medicina moderna nos fins do século XVII, período a partir do qual tanto o que era percebido pelos sentidos, como o que era escondido no interior do corpo foram testemunhados pelo olhar, descritos, revelados e traduzidos pela linguagem da emergente racionalidade clínica. A biomedicina se fundamenta numa racionalidade embasada em leis e princípios positivistas que classificam, enquadram e normatizam o homem e a sociedade a partir dos pressupostos das ciências naturais 15 . A racionalidade da biomedicina se baseia em três proposições que se vinculam à racionalidade da mecânica clássica, a qual isola as partes do todo para compreendê-las e, adiante, reintegrá-las ao seu mecanismo original 16: (1) o caráter universal e generalizante do discurso, secundarizando os casos individuais; (2) o caráter mecanicista na naturalização das máquinas criadas pelo homem e mecanização do universo, subordinando-o ao princípio de causalidade linear; (3) o caráter analítico no qual as leis gerais ou a leitura do todo é resultado da leitura das partes isoladas.

Na perspectiva biomédica, as doenças são entendidas como se fossem objetos com existência autônoma 16, expressas em lesões de uni ou multicausalidades, que alteram a morfologia e a dinâmica do corpo, tratáveis com substâncias que atinjam as causas das enfermidades. Os conhecimentos da morfologia e da fisiologia são parâmetros classificatórios do que é normal ou patológico na aparência e na dinâmica do organismo ${ }^{15}$. Os sintomas que não são constatados empiricamente são abandonados, porque são da ordem do metafísico, e esse campo não é considerado objeto da ciência clássica.

Hahnemann abandonou a medicina de sua época por insatisfação com o que ele considerava falta de princípios da terapêutica médica ${ }^{1}$. Com base em sua auto-experimentação, ele concluiu que a quinina curava, no homem portador da malária, os sintomas que ela tinha potencialidade para causar no homem saudável. O que causa o mal (doença artificial provocada pelo medicamento no experimentador) é capaz de curar o mal (a doença natural que acomete o doente). A partir dessa e de outras experiências, foram estabelecidos dois dos três princípios universais da homeopatia 17: (1) lei da similitude - o semelhante cura o semelhante; (2) experimentação no homem são.

O terceiro princípio - doses infinitesimais, o uso do medicamento diluído - foi descoberto na prática com seus pacientes. Inicialmente, ele tratava com doses ponderais, segundo a posologia farmacêutica da época, mas a freqüência e a intensidade das agravações eram constantes. Percebeu que à medida que diluía as doses, o efeito curativo persistia e as agravações tendiam a diminuir e a desaparecer, até que decresceu às doses infinitamente pequenas da substância matriz.

A terapêutica homeopática se diferencia de outros sistemas terapêuticos (alopático e do enantiopático) no raciocínio clínico, no tipo e na preparação do medicamento utilizado. O princípio da similitude expresso no aforismo "similia similibus curantur" (o semelhante cura o semelhante) é a sustentação filosófica da homeopatia, inspirada nos ensinamentos da medicina hipocrática 18 . O sistema médico homeopático se baseia nos mesmos conhecimentos anatômicos, fisiológicos e propedêuticos que são utilizados pela biomedicina, diferindo desta na abordagem semiológica e no ato de prescrição, como se constata na anamnese para tratamento homeopático ${ }^{19}$. No entanto, é na concepção de orga- 
nismo, saúde, doença e terapêutica que o compreender diferente é mais intenso e marcante, uma vez que o sistema terapêutico homeopático preconiza a busca integralizadora e holística do paciente e de sua realidade, no que diz respeito a sua dinâmica biopsíquica-relacional, tanto no adoecer, quanto no tratamento 20 . Assim dito, a doença não é a lesão; é, porém, um desequilíbrio no todo que se manifesta de múltiplas formas, que pode, inclusive, traduzir-se em lesão.

Para Hahnemann, esse todo dinâmico responsável pelo equilíbrio é a força ou energia vital: o atributo imaterial, automático, inerente ao homem, que coordena as funções orgânicas e psico-emocionais integralizando-as, tornando o homem uma unidade 17. Diferindo da biomedicina - cuja representação da enfermidade se encontra fortemente atrelada ao corpo biológico, que deve ser reparado para retornar ao seu automatismo na engrenagem sócio-econômica do existir e sobreviver 20 -, a medicina homeopática busca nos sintomas subjetivos o desvendar do todo que é o sujeito no seu processo particular, inter-relacional e coletivo de saúde e doença. $\mathrm{O}$ conhecimento da forma de ser e estar doente de cada um é revelado principalmente pela fala do paciente, segundo a representação que faz do próprio corpo, a qual traz o sintoma como consciência real de seu momento histórico, através de uma linguagem própria 19.

\section{Metodologia}

Foi realizado um estudo de caso com utilização de metodologias qualitativas em uma unidade de saúde do SUS, localizada em um bairro popular de Salvador, Bahia, Brasil, que oferece atendimento homeopático à população desde 1986 . A unidade foi escolhida por ser, atualmente, a única no serviço público na cidade a contar com profissional concursado no quadro regular exercendo rotineiramente a clínica homeopática.

O trabalho de campo se desenvolveu de janeiro a outubro de 2004, quando foram aplicados questionários, realizadas entrevistas semi-estruturadas e quando foi feita observação participante na sala de espera do consultório homeopático.

Para conhecer o perfil sócio-econômico dos usuários e a natureza das queixas que motivaram a busca da homeopatia, foi aplicado um questionário fechado a todas as pessoas que aguardavam a consulta com o homeopata entre os meses de março a julho de 2004. No total, foram aplicados 112 questionários. O questionário continha questões fechadas, visando a obter informação sobre idade, escolaridade, profissão/ocupação, cor, religião, renda familiar e tempo de tratamento com homeopatia, e uma questão aberta, a fim de obter a identificação das queixas que motivaram a consulta homeopática.

Entre os usuários que responderam ao questionário, foram selecionados os informantes para as entrevistas em profundidade. Essas entrevistas tiveram por objetivo conhecer as representações associadas à homeopatia, utilizando-se abordagem qualitativa adequada ao estudo do universo de significados, motivos, crenças, valores e atitudes 21 .

Na seleção dos informantes para as entrevistas, foram levados em conta critérios como o interesse e a disponibilidade para participar da pesquisa, além da capacidade de verbalização do informante. Procurou-se contemplar, no corpus, informantes de ambos os sexos, maiores de 18 anos e com maior ou menor experiência na homeopatia (pacientes na primeira consulta e pacientes com várias consultas). No total, foram realizadas 19 entrevistas em profundidade, empregando-se um roteiro semi-estruturado, no qual foram abordadas as motivações para a busca da homeopatia e as representações associadas aos medicamentos, ao tratamento e à consulta homeopática. As entrevistas foram gravadas e transcritas.

A análise dos dados privilegiou a compreensão e interpretação dos significados construídos nos discursos dos informantes à luz do seu contexto sócio-cultural 21. Foi realizada uma análise de conteúdo temática 21,22, na qual os dados das entrevistas em profundidade foram codificados segundo as categorias analíticas (motivação para a busca do tratamento homeopático, representações da homeopatia, do medicamento homeopático, da consulta homeopática e de saúde/doença), com abertura, no entanto, para a exploração de categorias nativas que, porventura, emergissem nos discursos. Para análise do questionário fechado, foi utilizado o programa Epi Info (Centers for Disease Control and Prevention, Atlanta, Estados Unidos).

Em consonância com os parâmetros do Conselho Nacional de Ética em Pesquisa (CONEP), o projeto que deu origem a este estudo foi aprovado pelo Comitê de Ética em Pesquisa, Instituto de Saúde Coletiva (ISC), Universidade Federal da Bahia (UFBA). Todos os participantes da pesquisa foram informados dos objetivos desta e dos seus direitos enquanto sujeitos participantes. A participação dos entrevistados somente era confirmada após o seu entendimento da explicação dos objetivos e dos procedimentos da pesquisa e depois de obtida a sua anuência. Para proteger a identidade dos participantes, todos os nomes apresentados neste estudo são fictícios. 


\section{Resultados e discussão}

\section{Perfil dos usuários da homeopatia}

Composta por 112 clientes do Serviço de Homeopatia, a população do estudo contava, na sua grande maioria, com mulheres (79\%), de cor predominante parda (54\%) e média de idade de 44 anos e 2 meses. A maior parte era constituída de pessoas nascidas na capital (55\%), todas residentes em bairros populares, que referiram ser adeptas do catolicismo (62\%). A escolaridade era baixa, considerando-se que $45 \%$ relataram não ter finalizado o ensino fundamental e trabalhar em profissões variadas e de pouca qualificação, principalmente serviços domésticos, no caso das mulheres. Quando não desempregadas, estavam inseridas no mercado informal com renda familiar de menos de dois salários mínimos (65\%).

Neste serviço, o tempo médio de tratamento homeopático foi estimado em quatro anos e sete meses. A grande maioria (78\%) procurou a homeopatia queixando-se de mais de um problema de saúde. Entre estas, as queixas mais comuns foram sintomas gerais e inespecíficos (24\%), problemas respiratórios (21\%), dores ósteo-musculares $(12 \%)$ e doenças de pele (12\%). Interessante notar que alguns pacientes fizeram menção a doenças, como problemas endócrinos, cistos e tumorações, que são consideradas pelos médicos homeopatas exemplos de limites terapêuticos da homeopatia 23 .

\section{Motivação para a busca da homeopatia}

A maior parte das pessoas entrevistadas não procurou a homeopatia em decorrência de um conhecimento prévio dessa prática terapêutica. A análise dos dados qualitativos mostra que o desconhecimento do que seja homeopatia é comum entre os usuários e entre os próprios servidores da unidade de saúde na qual o serviço é oferecido. Em geral, a procura da consulta homeopática pelos informantes se deu ao longo de um processo de busca de solução para um problema de saúde para o qual o tratamento convencional se mostrou ineficaz. Assim, a falência do tratamento alopático anterior constituiu-se na principal motivação para a busca da consulta homeopática entre as pessoas entrevistadas. Elas chegaram ao Serviço de Homeopatia através da indicação de familiares, amigos, vizinhos ou conhecidos que tiveram uma experiência positiva com essa prática terapêutica e a recomendaram. Alguns informantes relataram, ainda, ter recebido indicação para a homeopatia por parte dos médicos com os quais anteriormente se tratavam.
“Os médicos, eu já levei em mais de oito pediatras e eles dizem que não são especialistas, então não dá jeito. Mandam levar no médico homeopático, que só ele poderia passar o remédio porque eles é que sabem quais. Um alergista também mandou levar no homeopático..." (Alexandra, 25 anos, mãe de Mateus, 2 anos).

Os achados deste estudo corroboram o que foi encontrado por Mendicelli 24 na cidade de São Paulo, com população semelhante. Segundo a autora, do total da população entrevistada, $56,7 \%$ desconhecia que o Serviço de Homeopatia era oferecido nas unidades de saúde investigadas; $58,5 \%$ receberam indicação do tratamento homeopático por meio de parentes, amigos e conhecidos, enquanto $66,3 \%$ buscaram a homeopatia por falha do tratamento anterior. Os achados contrastam, no entanto, com os resultados da pesquisa realizada por Loyola 3 junto às pessoas de classe média que fazem consultas homeopáticas em consultórios particulares. Neste caso, a demanda espontânea ao tratamento homeopático aparece como preponderante, motivada por uma tendência de confrontação ao tratamento alopático hegemônico. No caso da população de baixa renda que utiliza o serviço homeopático no SUS entrevistada neste estudo, a homeopatia é menos uma escolha ideológica e mais uma busca pragmática de uma alternativa terapêutica para a solução de um problema de saúde que a medicina tradicional não conseguiu resolver.

\section{Representações do tratamento homeopático}

A visão do tratamento homeopático como natural foi a representação mais recorrente no discurso das pessoas entrevistadas, mesmo entre aquelas que aguardavam na sala de espera pela primeira consulta. A noção de natural se relaciona com o que é produzido pela natureza, em oposição a aquilo que é fabricado, que é químico, sintético, artificial. O medicamento homeopático foi descrito pelas pessoas como análogo aos medicamentos fitoterápicos, que são naturais, pois utilizam plantas, folhas e raízes. Os elementos da natureza são vistos como saudáveis, não prejudiciais e até vitais, como é o caso da água: "Tratamento natural no meu entender é quando a gente busca [remédios] de folhas, de raízes. Essas coisas é um tratamento natural porque são medicamentos que vêm das plantas ou de legumes e verduras, e no tratamento homeopático eu não entendo bem, eu sei que usa água, uma coisa natural também, não sei explicar" (Rute, 36 anos).

De maneira geral, as pessoas entrevistadas desconhecem a origem do medicamento homeopático e sua forma de preparação. Ele se aproxima e se insere, no entanto, no universo cultural 
das classes populares a partir da relação que as pessoas estabelecem entre o remédio homeopático e os elementos da natureza que estão presentes nos chás, infusões, banhos e garrafadas preparadas sob orientação das raizeiras, benzedeiras, mães e pais de santo na medicina tradicional e nas práticas religiosas 5 .

A representação do medicamento homeopático como natural e não prejudicial à saúde está em oposição à representação dos medicamentos alopáticos como artificiais e passíveis de causarem sintomas desagradáveis ou dano a outros órgãos do corpo que estavam sadios.

"Tomo Puran de 100 e Captopril para tireóide, coração e pressão alta. Estou tomando comprimido por causa do problema, mas a homeopatia é mais natural. Para evitar ficar tomando comprimido, porque a gente melhora de uma coisa e piora de outra e a homeopatia é mais natural. Ameniza mais o problema, porque evita de tomar os comprimidos e até o estômago se sente melhor no tratamento, a gente não sente dor" (Lídia, 46 anos).

Para a maioria dos informantes, o remédio homeopático age de forma lenta, o que está associado ao fato de ser natural e agir respeitando o ritmo da natureza. É interessante notar que a ação lenta do medicamento homeopático passa a adquirir uma série de significados positivos. Segundo os entrevistados, ao agir em consonância com a natureza, ele não perturba o ritmo do organismo, o que explica a ausência de efeitos colaterais. Sua ação lenta, mas equilibrada e profunda, é vista em oposição à ação rápida, mas, por vezes, agressiva e superficial, dos remédios alopáticos. O imediatismo atribuído a estes últimos é visto pelos informantes como uma violência ao estado fisiológico do corpo. A maior demora na ação do tratamento homeopático está associada ao tempo necessário para que se descubra a verdade mais fundamental sobre a pessoa e seu sofrimento. É necessário tempo para agir sobre o que não está acessível superficialmente, pois é preciso ir lá no fundo buscar a origem da coisa para poder proceder a uma cura profunda ou, no dizer de um informante, para que se descubra a realidade da vida.

"Eu acho que ele é lento mesmo. Os outros remédios que você toma para dor passa logo e ele não. Ele vai devagarzinho, vai lá no fundo buscar a origem da coisa, onde se encontra mesmo a doença, para poder curar. Por exemplo, eu dava crise, me curou, nunca mais eu dei crise de noite, nunca mais" (Joana, 57 anos).

"Ele tem o resultado aos poucos, a gente vai vendo o resultado e ele age de uma forma bem natural. É devagar. Não é no caso de um antibiótico que a gente usa hoje e hoje mesmo eu já vou ver o resultado. Tem que esperar o resultado, mas o resultado é mais certo e não é agressivo" (Rute, 36 anos).

A lógica do tempo no tratamento homeopático contrapõe-se ao imediatismo e à velocidade característicos da modernidade globalizada. A rapidez do tratamento e dos medicamentos alopáticos, referida em muitos discursos dos entrevistados, ajusta-se ao ritmo da vida moderna, no qual as soluções devem chegar velozmente, uma vez que se vive sob a influência do fator econômico. A rápida remissão dos sintomas é importante para que os pacientes possam voltar a desempenhar normalmente suas atividades cotidianas e, sobretudo aqueles que são trabalhadores, possam retornar ao trabalho na maior brevidade.

Queiroz 25, em estudo realizado com usuários do SUS em Paulínia, São Paulo, discute como essa lógica reflete-se na expectativa, em relação ao médico, para a utilização de remédios potentes capazes de erradicar o mal de forma quase instantânea e representa dificuldade para médicos do SUS que defendem uma ação terapêutica menos medicalizada. Esses resultados, contudo, mostram que os usuários da homeopatia não apenas aceitam a ação mais lenta dos medicamentos homeopáticos, como valorizam positivamente essa temporalidade. É possível que o fato de muitos dos informantes serem donas de casa ou aposentados e, portanto, não sofrerem pressão direta de empregadores para rápida solução do problemas de saúde e retorno imediato ao trabalho favoreça a aceitabilidade de um tempo de tratamento mais longo.

A noção de ser lento está vinculada também à abrangência holística do tratamento e da ação do medicamento homeopático, que age no sujeito em sua totalidade (extensão e profundidade), sem agredir parte alguma de seu todo não segmentado. No processo terapêutico, qualquer adoecimento expresso em sinais ou em sensações é entendido como manifestação do ser integral.

"Conforme eu falei, ele [o medicamento] pode demorar um pouquinho mais do que o analgésico, mas ele trata como um todo. (...) Então eu tomo o remédio da alopatia para dor de cabeça, só a dor de cabeça vai ser passada, mas acontece que a dor do meu pé não vai ser passada com aquele remédio que eu tomei por causa da dor de cabeça. Ao passo da homeopatia, que eu estou tomando o remédio para nervoso, mas ele trata o problema do meu rim, do meu útero, do meu ovário e assim sucessivamente" (Sabina, 40 anos).

Nessa representação do que é lento, emerge, também, a noção de um tratamento que é voltado para toda uma vida, que tem um tempo indefinido de existência, demandando trata- 
mento continuado. Aliado a isso, está o tempo de que se necessita para curar cada um dos novos sintomas que surgem, enquanto viver o sujeito, não importando se os seus sinais e sintomas surgiram na sua infância, adolescência, juventude, maturidade ou senilidade. Essa abordagem não segmentada na dinâmica biopsicossocial pode ser entendida como holismo ou integralidade horizontal 4 , que acontece quando se busca, sem recortes temporais, o conhecimento do sujeito desde a sua vida intra-uterina até ao momento da consulta 4. Ambas as formas semiológicas são contempladas simultaneamente na terapêutica homeopática, que não compartimentaliza o sujeito na sua dinâmica biopsicocultural, nem faz um recorte temporal de sua vida, uma vez que entende que o sujeito é um todo funcional em qualquer momento de sua existência e não apenas uma parte adoecida 17.

"É uma consulta que de fato vai buscando em você, vai cavando de fato lá do início da sua vida, ou até da gravidez da nossa mãe, né?" (Bete, 56 anos).

"Ele fazia um montão de pergunta, de tudo como era minha vida, do princípio ao fim..." (Lídia, 43 anos).

A abordagem holística da homeopatia encontra boa receptividade entre os usuários do SUS entrevistados, por se encontrar em consonância com o holismo característico das práticas médicas populares e religiosas. De forma semelhante ao que ocorre nas religiões populares, a exemplo do candomblé, das igrejas pentecostais, do catolicismo e espiritismo populares, o médico homeopata não se centra apenas no corpo físico e nos processos fisiopatológicos; ele busca, nas várias dimensões da vida do paciente, os elementos que contribuem para explicar a origem dos problemas de saúde 10 .

“Ah, eu acho uma consulta ótima porque ela envolve, assim, um monte da psicologia humana. Ela pergunta todo o seu funcionamento físico, se você evacua bem, se você dorme bem, se você come bem, né? Aí depois ela passa assim, se tem medo, tem temores, sonha muito? Então ela procura ver o seu lado físico, procura ver o lado espiritual, o que você pensa a respeito da vida. Somos corpo e somos espírito, então se um não trabalha com o outro não vai ter resultado de positividade" (Lúcia, 45 anos).

Por fim, o baixo custo do tratamento homeopático foi trazido também pelos informantes como importante aspecto para adesão a essa terapêutica. O preço médio do medicamento homeopático, em gotas ou glóbulos, nas dinamizações mais prescritas, gira em torno de menos de $2 \%$ do salário mínimo, que na época do estudo valia duzentos e sessenta reais, podendo durar mais de trinta dias, mesmo sendo utilizado de duas a três vezes por dia.

\section{Representações da consulta homeopática}

A visão que os informantes trazem da consulta homeopática é construída em oposição ao referencial que possuem da consulta para o tratamento alopático. Alguns informantes mantêm o tratamento biomédico em paralelo ao homeopático por conta da gravidade de sua doença, que não pode prescindir dos medicamentos alopáticos. Os entrevistados percebem, no entanto, a situação marginal da homeopatia em face da biomedicina: "Quando eu voltei para o mastologista para falar que eu tinha ficado boa do cisto da mama com o remédio da homeopatia, ele deu gargalhada, chicanando que a homeopatia não cura. Pra mim, cura!" (Anita, 63 anos).

O que é marcante nos discursos, porém, é o espaço diferenciado que a consulta homeopática representa, durante a qual os entrevistados referem poder falar tudo o que sentem, com calma, e sem pressa. O tempo longo da consulta homeopática foi considerado pelos informantes como uma característica diferencial importante em relação às consultas médicas alopáticas. A escuta atenta à narrativa do paciente pelo médico homeopata é percebida pelos informantes como um ato de atenção e de respeito, que contrasta com a consulta apressada e pouco dialógica na clínica biomédica. Esta última foi descrita por uma informante como aquela na qual o médico não olha o paciente e não faz as perguntas que ele gostaria de responder.

"O médico nos ouvir com paciência, é procurar detalhadamente cada coisa que sentimos. Eu tenho 66 anos conforme falei; durante esses anos eu fui em 'médicos químicos' e que infelizmente, quando eu sentava, o médico já estava com a receita praticamente pronta, nem sequer me ouvia. Ao contrário da homeopatia, que lhe ouve com paciência detalhadamente" (Narcisa, 66 anos).

O valor da escuta no processo terapêutico da biomedicina é geralmente voltado para se focar na informação trazida pelo paciente que se presta à diagnose; tudo que não cumpre esse fim é ignorado, ou visto como ignorância e crendice popular. O pragmatismo do ouvido clínico não reconhece o valor terapêutico de uma consulta quando ao sujeito é dada uma escuta mais abrangente e menos focal. Segundo Caprara \& Rodrigues 26 , estudos mostram que $25 \%$ dos benefícios oriundos da prática médica não estão relacionados com a qualificação tecnológica do médico ou com os efeitos terapêuticos dos medicamentos ou do placebo, mas com os efeitos terapêuticos da própria palavra do médico, sobre 
uma série de sintomas que surgem como eventos ligados aos fenômenos de estresse (cefaléia, cansaço, constipação, problemas gástricos, modificações do peso etc.). Esses autores chegaram à conclusão de que o maior tempo de consulta favorece uma melhor qualidade de atendimento, que se caracteriza por uma melhor anamnese: "uma melhor explicação do problema e dos procedimentos diagnósticos e terapêuticos, assim como a verificação do médico sobre a compreensão do paciente e a participação do paciente na consulta" 26 (p. 143-4).

Vale pontuar que a satisfação com a consulta homeopática, em virtude da atenção do profissional, do tempo de duração, da boa vontade do médico em perguntar e ouvir, foi expressa por um dos informantes como uma consulta de qualidade, diferenciada, como se fosse uma consulta particular. Essa afirmação expressa a insatisfação com a precariedade da assistência médica na rede pública, onde, além da lógica tecnicista própria da racionalidade biomédica 1 , diversos fatores estruturais e grande demanda por atendimento impactam diretamente no tempo disponível para a consulta e na qualidade do encontro terapêutico. O tratamento homeopático no SUS representa, para os informantes, um momento e um espaço que não se sujeita a essa lógica, no qual eles se sentem como se estivessem recebendo atenção e respeito de forma semelhante à que eles imaginam recebam as pessoas que financiam uma consulta em um consultório particular.

É importante ressaltar, entretanto, que o tempo diferenciado da consulta é próprio da racionalidade homeopática. A semiologia que conduz à terapêutica homeopática leva o médico a ouvir, a dar tempo ao paciente para pensar, observar-se, autodescobrir-se e revelar-se para o médico 27 . Não é uma mera manifestação do perfil humanista do médico, mas uma imposição semiológica para se completar o raciocínio clínico. O interrogatório que embasa a anamnese da homeopatia busca nos eventos orgânicos e emocionais do passado causas desencadeantes da enfermidade que motiva a consulta 27 ; é por isso que se precisa de tempo para "conhecer a pessoa, cobrir a totalidade do paciente, fazer o diagnóstico do medicamento homeopático, conhecer as sensibilidades do paciente, respeitando o relato espontâneo e travar uma relação de empatia" 28 (p. 16-7).

\section{Considerações finais}

Os resultados deste estudo mostram que o tratamento homeopático foi bem avaliado pelos usuários do SUS entrevistados com base em sua experiência pessoal. A proximidade da filosofia homeopática com aspectos das práticas populares e religiosas de saúde, tal como a perspectiva holista, o uso de medicamentos naturais e a escuta aberta e atenta ao discurso do paciente, favorece a aceitação e a incorporação de elementos simbólicos da homeopatia pelos usuários das classes populares. Estes percebem a situação marginal da homeopatia em relação à medicina hegemônica e respondem enfatizando a natureza não iatrogênica dos medicamentos homeopáticos e a ação de cura lenta, mas profunda, que eles permitem. Para a maior parte dos entrevistados, a principal motivação para a procura do tratamento homeopático foi o insucesso do tratamento alopático anterior. A migração terapêutica para a homeopatia, a adesão ao tratamento e a propaganda do serviço para outros pacientes pode ser compreendido como uma resistência ética, conforme o proposto por Luz ${ }^{13}$. Ela é a forma pela qual esses indivíduos das classes populares encontram meios de dar materialidade à sua crítica à biomedicina dominante, que não lhe traz sensação de familiaridade e com a qual eles não se identificam, não se reconhecendo no que lhes é oferecido.

Os resultados do estudo apontam, de um lado, para a necessidade de maior humanização da prática biomédica, em especial a atenção à subjetividade do paciente, e, de outro, para o potencial ainda pouco explorado da contribuição de alternativas terapêuticas como a homeopatia no serviço público de saúde. 


\section{Resumo}

Apesar de ter sido oficialmente introduzida no Brasil em 1840, a homeopatia só foi reconhecida pelo Conselho Federal de Medicina como uma especialidade médica em 1980. Sua presença no Sistema Único de Saúde (SUS) ainda é reduzida, existindo poucas experiências de serviços de homeopatia em não muitos municípios brasileiros. Este estudo tem como objetivo conhecer as representações dos usuários do SUS sobre a homeopatia. A metodologia da pesquisa foi qualitativa, tendo sido realizado um estudo de caso em uma unidade de saúde em Salvador, Bahia. Para a coleta de dados, foram aplicados 112 questionários aos usuários do serviço de homeopatia na unidade selecionada, com os quais foram realizadas 19 entrevistas em profundidade. Os resultados do estudo mostraram que a principal motivação para a procura da homeopatia foi o insucesso do tratamento alopático anterior. A perspectiva holística, o uso de medicamentos naturais, o tempo longo da consulta e a escuta atenta do paciente foram trazidos como características diferenciais positivas na comparação com o tratamento alopático. Os resultados apontaram para o potencial ainda pouco explorado da contribuição de alternativas terapêuticas como a homeopatia, no SUS.

Homeopatia; Representações Sociais; Sistema Único de Saúde; Terapias Complementares

\section{Referências}

1. Luz MT. A arte de curar versus a ciência da doença - história social da homeopatia no Brasil. São Paulo: Dynamis Editorial; 1996.

2. Fortes L. A institucionalização da homeopatia no Brasil e na Alemanha: uma análise sociológica dos conflitos e convergências entre seus agentes [Tese de Doutorado]. Brasília: Universidade de Brasília; 2000.

3. Loyola MA. Uma medicina de classe média: idéias preliminares sobre a clientela da homeopatia. Cadernos do IMS 1987; 1:46-72.

4. Monteiro DA. O ta[lento] da homeopatia: representações dos sujeitos no SUS [Dissertação de Mestrado]. Salvador: Instituto de Saúde Coletiva, Universidade Federal da Bahia; 2005.

5. Montero P. Da doença à desordem: a magia na umbanda. Rio de Janeiro: Graal; 1985.

\section{Colaboradores}

D. A. Monteiro e J. A. B. Iriart participaram igualmente de todas as etapas da elaboração do artigo.
6. Donangelo MCF. Saúde e sociedade. São Paulo: Livraria Duas Cidades; 1979.

7. Paim J, Almeida Filho N. A crise da saúde pública e a utopia da saúde coletiva. Salvador: Casa da Qualidade Editora; 2000.

8. Comissão de Saúde Pública, Associação Médica Homeopática Brasileira. Relatório da Comissão de Saúde Pública. In: Anais do XXIV Congresso Brasileiro de Homeopatia. Gramado: Associação Médica Homeopática Brasileira (AMHB); 1998.

9. Queiroz MS. Saúde e doença: um enfoque antropológico. Bauru: Edusc; 2003.

10. Iriart JAB. Concepções e representações da saúde e da doença: contribuições da Antropologia da Saúde para a Saúde Coletiva. Salvador: Instituto de Saúde Coletiva, Universidade Federal da Bahia; 2003. 
11. Kleinman A. Patients and healers in the context of culture. Berkeley: University of California Press; 1980.

12. Luz MT. Racionalidades médicas e terapêuticas alternativas. Cadernos de Sociologia 1995; 7:109-28.

13. Luz MT. Novos saberes e práticas em saúde coletiva: estudo sobre racionalidades médicas e atividades corporais. São Paulo: Editora Hucitec; 2003.

14. Foucault M. O nascimento da clínica. Rio de Janeiro: Forense Universitária; 1987.

15. Canguilhem G. O normal e o patológico. Rio de Janeiro: Forense Universitária; 1978.

16. Camargo Jr. KR. A biomedicina. Physis (Rio de J) 1997; 7:45-68.

17. Hahnemann S. Doenças crônicas. 3a Ed. São Paulo: Artes Gráficas Giramundo; 1990.

18. Duprat H. A teoria e a técnica da homeopatia. Rio de Janeiro: Gráfica Olímpica Editora; 1974.

19. Monteiro DA. Sintoma - o dialeto de cada um. In: Nassif RG, organizadora. Compêndio de homeopatia. v. III. São Paulo: Robe; 1997. p. 232-7.

20. Monteiro DA. O corpo e o sintoma na semiologia homeopática. Rev Homeopat 2002; 4:131-6.

21. Minayo MC. O desfio do conhecimento: pesquisa qualitativa em saúde. Rio de Janeiro: ABRASCO/ São Paulo: Editora Hucitec; 1996.
22. Bardin L. Análise de conteúdo. Lisboa: Edições 70; 1979

23. Salles SA. O perfil do médico homeopata [Dissertação de Mestrado]. São Paulo: Universidade de São Paulo; 2001.

24. Mendicelli VLLM. Homeopatia: percepção e conduta da clientela de postos de saúde em São PauloSP [Tese de Doutorado]. São Paulo: Faculdade de Saúde Pública, Universidade de São Paulo; 1994.

25. Queiroz MS. Estratégias de consumo em saúde entre famílias trabalhadoras. Cad Saúde Pública 1993; 9:272-82.

26. Caprara A, Rodrigues J. A relação assimétrica médico-paciente: repensando o vínculo terapêutico. Ciênc Saúde Coletiva 2004; 9:139-46.

27. Araújo EC. O processo terapêutico da medicina homeopática - o papel estratégico da relação médico-paciente [Tese de Doutorado]. São Paulo: Universidade de São Paulo; 2001.

28. Luz HS, Campello MF. Homeopatia. In: Anais do VI Seminário do Projeto Racionalidades Médicas. Rio de Janeiro: Instituto Hahnmanniano do Brasil/Instituto de Assistência dos Servidores do Estado do Rio de Janeiro, 1997. p. 4-39.

Recebido em 21/Jun/2006

Versão final reapresentada em 12/Fev/2007

Aprovado em 15/Fev/2007 